\title{
PRÁTICA PROJETUAL EM DESIGN DE AMBIENTES: RELATO DE EXPERIÊNCIA SOBRE A INSERÇÃO DA METODOLOGIA APLICADA À COMPLEXIDADE
}

\author{
Isabella Pontello Bahia \\ Universidade do Estado de Minas Gerais \\ isabellapont.bahia@gmail.com \\ Sâmela Suélen Martins Viana Pessôa \\ Universidade do Estado de Minas Gerais \\ samelasuelen@gmail.com \\ Francislaine da Costa Rosendo \\ Universidade do Estado de Minas Gerais \\ franrosendo@yahoo.com.br \\ Anna Laura Scarabelli Fernandes \\ Universidade do Estado de Minas Gerais \\ annalaurascarabelli@gmail.com
}

RESUMO: O estudo em questão tem como cerne a proposta de abordagem da metodologia de projeto empregada no curso de design de ambientes da Universidade do Estado de Minas Gerais (UEMG). Tem como objetivo retratar as peculiaridades do design enquanto atividade projetiva para a constituição de ambientes, bem como ilustrar a proposta de projeto aplicado atualmente na disciplina de prática projetual. $O$ artigo, assim como a metodologia, contempla as questões abstratas e complexas as quais o projeto de design se depara na atualidade. Parte da compreensão de que o curso de design de ambientes da UEMG tem empregado uma metodologia antiga que ainda se baseia em conteúdos previsíveis e traz consigo uma maneira linear de projetar. Dessa forma pretende, pois, fazer um panorama da inserção da metodologia no curso de design de ambientes, compreendendo o próprio curso e a evolução dos questionamentos em design de ambientes no que tange os aspectos metodológicos.

Palavras-chave: design de ambientes; metodologia; complexidade; prática projetual.

ABSTRACT: This papper has as its heart the proposed methodology's approach in the project interior design course of State University of Minas Gerais. Aims to portray the peculiarities of the design while activity for interior projective, as well as illustrate the proposal applied project currently in the discipline of design practice. The article, as well as the methodology, contemplates the abstract and complex issues which the project facing design today. Part of the 
understanding that interior design course of State University of Minas Gerais has employed a methodology that still relies on content predictable and brings with it a linear way of designing. In this way want to therefore an overview of the methodology in the course of design of environments, including the course itself and the evolution of the questions in interior design related aspects methodology.

Key-words: interior design; methodology; complexity; project practice.

\section{INTRODUÇÃO}

A prática projetual em design é uma disciplina que recebe significativo destaque nas grades curriculares dos cursos de design. Implica na aglutinação de diversos conteúdos ministrados ao longo do curso em uma experimentação teórico-prática. Compreende-se que esta disciplina confere aos designers em formação bases para o exercício prático da profissão, associados aos pré-requisitos normativos e metodológicos que orientam o desenvolvimento de soluções em design.

Por meio de uma análise inicial a cerca dos métodos propostos por teóricos do design ao longo das últimas décadas, pode-se verificar como esses modelos se configuraram em uma estrutura linear e até a atualidade são utilizados como referência de ensino para a formação de designers. Contudo, o design na atualidade se configura como atividade interdisciplinar, que demanda um olhar holístico e que seja capaz de pensar problemas de um cenário interconectado e complexo. Nesse sentido, a metodologia do design, outrora desenhada em um fluxo linear previsível, hoje se depara com um cenário de conexões e sistemas que exigem relacionar diferentes conhecimentos e fontes do saber.

Ao refletir a respeito da metodologia aplicada ao design no Curso de Design de Ambientes da Universidade do Estado de Minas Gerais (CDA/UEMG) verifica que era um processo linear que não se aplica à medida que a complexidade aumenta, sendo necessária a incorporação de novos modelos. Assim, o presente artigo, busca compreender os marcos de evolução do atual CDA/UEMG, a partir da análise de pesquisa documental, referencial bibliográfico e atividades de co-participação com os alunos da Prática projetual de design de ambientes da UEMG. Essa pesquisa foi feita a partir da análise do projeto pedagógico do curso, da ementa e conteúdo dos programas da atual disciplina de Prática Projetual I e o marco de inserção da disciplina de metodologia do design na grade curricular.

Em sequência, irá apresentar um ensaio experimental realizado na disciplina de Prática Projetual I do CDA/UEMG. Esse relato resulta de abordagens teórico-práticas realizadas na disciplina e de reflexões a cerca dos desdobramentos da metodologia do design frente às complexidades do cenário atual. Nesse sentido, analisar as mudanças pelas quais a metodologia do design passou ao longo das últimas décadas permite compreender a necessidade de criar um espaço, dentro do ambiente acadêmico, para discussão, reflexão e proposição de novos modos para se conduzir o processo de design no contexto atual. 


\section{DESIGN DE AMBIENTES E A PRÁTICA PROJETUAL}

\subsection{Definições e parâmetros}

O termo Design tem diversas definições por ser um termo que origina-se de outro idioma e abrange varias áreas enquanto inserido na língua portuguesa. É considerado uma atividade multidisciplinar que reúne atributos da arte e da ciência, do intuitivo e do cientifico, cujo objetivo é proporcionar benefícios à sociedade. O design cria sinais, redefine formas, agrega valor aos artefatos industriais e é capaz de transformar desejos do inconsciente em objetos materiais, resolver problemas, promover a experiência emocional, cognitiva e estética, assim como proporcionar o bem estar do usuário, de maneira sistemática e criativa (MOZOTA, 2011; MORAES, 2010, VIANNA, 2012).

A partir da compreensão destes conceitos de design, esse artigo considerará o designer como solucionador de problemas. Essa mesma definição foi apresentada na 29a Assembléia Geral do International Council Societies of Industrial Design (ICSID) realizada em outubro de 2015 em Gwangju na Coréia do Sul, em que o comitê de prática profissional caracterizou o design industrial da seguinte forma:

\footnotetext{
"Design Industrial é um processo estratégico de resolução de problemas que impulsiona a inovação, constrói o sucesso do negócio e leva a uma melhor qualidade de vida através de produtos inovadores, sistemas, serviços e experiências." (ICSID, 2015).
}

Consideramos então o design como uma disciplina holística que através de uma análise crítica da realidade consegue atribuir aos objetos, serviços ou ambientes, aspectos intangíveis, valores, sentidos, provocar reações e interações entre humano, objeto e ambiente.

Dentre as tipologias do design encontra-se o design de ambientes que de forma similar ao design industrial pode ser definido como uma atividade multidisciplinar que visa solucionar problemas entre humano e o espaço, entendendo que neste caso a interface consiste no espaço; sendo este residencial, empresarial, institucional, industrial, arquitetônico, efêmero, externo e virtual.

A formação de designer de ambientes tem como enfoque principal o atendimento às questões funcionais e estéticas que se apresentam no espaço onde são exercidas as atividades humanas e o projeto - produto final que se pretende, é determinante da melhoria da qualidade de vida. (FRANCO e ARAÚJO, 2003, p.09).

Designers de ambientes são, pois, os profissionais que projetam ambientes considerando o usuário no centro do processo, levando em consideração os aspectos funcionais, ergonômicos e estéticos, bem como os aspectos históricos, culturais, sociais, econômicos de acordo com cada demanda, sempre buscando como resultado um ambiente que expresse visualmente suas idéias, transmita a identidade dos usuários e preze pelo bem estar e pela qualidade de vida (ABREU, 2015; MOREIRA, 2006).

Observa-se, pois, que de forma comum entre as tipologias do design está a disciplina de prática projetual. Ou seja, a atividade do designer perpassa pela construção de um pensamento projetual (DIAS, 2004). Ainda que não especificamente compreendida como o desenvolvimento de projetos palpáveis a prática consiste na materialização do pensamento e dos desdobramentos compreendidos na solução de problemas. Dessa forma se faz necessário abordar o entendimento acerca da prática e a compreensão da 
relevância de tal disciplina dentro da grade curricular dos cursos de design e, aqui em foco, enquanto imerso no curso de design de ambientes da UEMG.

\subsection{A prática projetual em design de ambientes}

A palavra prática provém do Latim, practice, e no idioma Grego define-se como praktiké, que trás a idéia da "Ciência prática, em oposição à Ciência especulativa" (Enciclopédia da Conscienciologia, s,d.) que surgiu como vocábulo no século XV. Enquanto ciência prática entende-se, pois, que consiste em uma terminologia associada diretamente ao fazer, ainda que a conexão e interdependência com as ciências a faça ser uma atividade formal inserida em um contexto acadêmico. Bordieu, em "Esboço de uma teoria da prática" (1972), propõe uma teoria que compreende, articula e atua na prática, em que é possível compreender que a prática (teorizada) nada mais é do que "entender a vida social enquanto produto das condições materiais e culturais bem como das práticas e experiências coletivas e individuais" (CASANOVA, 1995). Ou seja, trata-se do fazer imerso em um universo social, o qual apresenta peculiaridades e intenções diversas.

Enquanto inseridos no contexto acadêmico de ensino do design, e aqui em foco no ensino do design de ambientes, observa-se a ocorrência e repetição, ainda que pregnante, no currículo do curso de design a disciplina de Prática Projetual. Definida no Projeto Pedagógico do curso de Design de Ambientes (FRANCO e ARAÚJO, 2004, p.44) como o "planejamento e desenvolvimento de projetos de várias complexidades como instrumento para experimentar e verificar metodologias e aplicações tecnológicas" a disciplina é caracterizada por conciliar elementos teóricos com o fazer em design auxiliados diretamente pela metodologia de projeto em design.

Para Dias (2004) a disciplina de Projetos é considerada a espinha dorsal dos cursos de Design. Questão que justifica-se pelas competências trabalhadas na disciplina que possibilitam a conexão entre a prática e a teoria e a materialização do imaterial.

$\mathrm{Na}$ disciplina de Projetos, o procedimento metodológico adotado é o "aprendizado por meio de exemplos", no qual as soluções dos problemas e as tomadas das decisões aumentam em função da sua complexidade. Segundo Bonsiepe (1997), até hoje não temos critérios confiáveis para determinar a complexidade de problemas projetuais. A complexidade estrutural e funcional não permite estimar o grau de dificuldade de um problema (DIAS, 2004, p.80).

No CDA/UEMG a prática projetual contempla a compreensão e aplicação de princípios que direcionam e analisam os espaços a serem projetados. De acordo com (FRANCO; ARAÚJO, 2003), no Projeto de Reforma Curricular, a proposta da disciplina contempla a compreensão das várias possibilidades de ambientes, bem como 0 entendimento dos questionamentos da sociedade a serem respondidos através do design. Tal questão nos permite duas percepções: a primeira de que a prática projetual em design de ambientes deve estar conectada com elementos do cotidiano social e a segunda de que os princípios que orientam o projeto de ambientes consistem na metodologia de projeto. Metodologia esta que só foi inserida na prática projetual no ano de 2004, mediante alteração no projeto pedagógico, e que enquanto ementa e estrutura se mantém a mesma até os dias de hoje.

Assim cabe analisar que diante às constantes mudanças da sociedade rumo a configuração de um cenário complexo, Cardoso (2013) afirma que a metodologia do design, construída para a resolução de problemas da indústria e do mercado, se volta para refletir sua capacidade de proposição de soluções de uma maneira mais holística e 
sistêmica (CARDOSO, 2013; MORAES, 2010; CELASCHI e MORAES, 2013). Nesse sentido, compreender as mudanças pelas quais a sociedade passou ao longo das últimas décadas permitirá identificar os rumos para uma nova configuração capaz de atender as complexidades do cenário atual.

\section{ESTRUTURA METODOLÓGICA DO DESIGN E SEUS DESDOBRAMENTOS RUMO À COMPLEXIDADE}

A década de 1960 foi o período em que se concentrou as principais referências de sistematização do processo de design. Esses modelos se perpetuaram até a atualidade e se caracterizam pela predominância das etapas: compreensão e definição do problema; coleta das informações; análise das informações; desenvolvimento dos conceitos de soluções alternativas; avaliação e reavaliação das alternativas; seleção da solução; teste e implementação (VAN DER LINDEN e LACERDA, 2012). Os modelos metodológicos apresentados por vários teóricos do design nas últimas décadas, dentre eles Bonsiepe (1983), Maldonado (1999), Cardoso (2000), Lobach (2001), Burdek (2006), Bezerra (2008), Baxter (1998), contribuíram para a estruturação de um processo linear de desenvolvimento de soluções e que na atualidade vem sendo objeto de estudos.

Sobre esses modelos metodológicos apresentados nas últimas décadas, compreende-se que trouxeram significativas contribuições para a construção de parâmetros que conduziram as etapas de desenvolvimento dos processos de design. A linearidade contida nos modelos considerava um processo previsível e com etapas bem determinadas que se desencadeavam em direção a implementação de uma solução. $\mathrm{Na}$ medida em que a complexidade do cenário foi se transformando e novos modelos foram sendo incorporados na sistematização da metodologia do design, como pode ser analisado nas referências que serão apresentadas.

Pode-se notar inicialmente que o processo de design se organizou em macro etapas que compreenderam as fases analítica, criativa e executiva. A estrutura deste processo de design se configura em três momentos distintos detalhados como: fase analítica - que compreende o raciocínio indutivo; a fase criativa - que envolve o raciocínio dedutivo; e a fase executiva - que visa à descrição da intenção. Pode-se perceber que ao longo desse processo foi possível incluir formalmente a intuição e a criatividade no contexto do fluxo metodológico do design (CROSS, 2008; VAN DER LINDEN; LACERDA, 2012). Um modelo proposto por Bonsiepe (1984), e que é considerado referência para o ensino e prática da metodologia projetual na atualidade pode ser observado na figura 1:

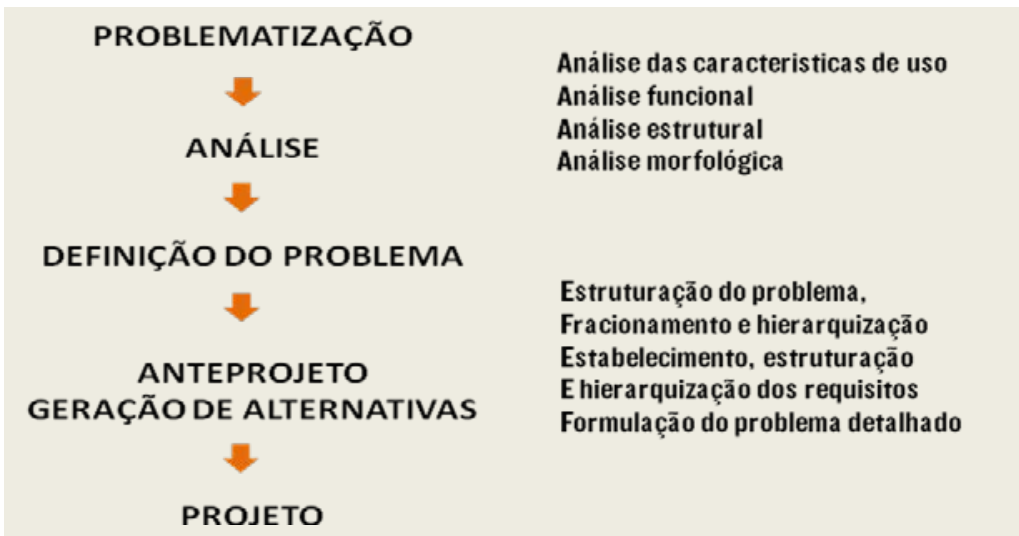

Figura 1: Fluxo Linear de BONSIEPE (1984); VAN DER LINDEN; LACERDA (2012). Fonte: BONSIEPE (1984) e elaborado pelo autor, 2016. 
No modelo de Bonsiepe (1984) o problema ganha ênfase na estrutura metodológica, na qual a problematização introduz o pensamento analítico que se direciona a hierarquização dos requisitos e a formulação de um problema detalhado de design. Em sequência surge a geração de alternativas que compreende uma etapa criativa orientada a geração da solução. A linearidade apresentada na figura aponta para o fato de que esse modelo não possibilita a visualização das interações sucessivas para que o problema e a solução sejam modelados considerando as complexidades.

Abaixo será apresentado o método de March (1984) referenciado por Van Der Linden e Lacerda (2012) que foi um modelo que rompeu com a concepção linear dos fluxos, partindo da visão de que o problema é dependente da solução, conforme pode ser observado na figura 2 :

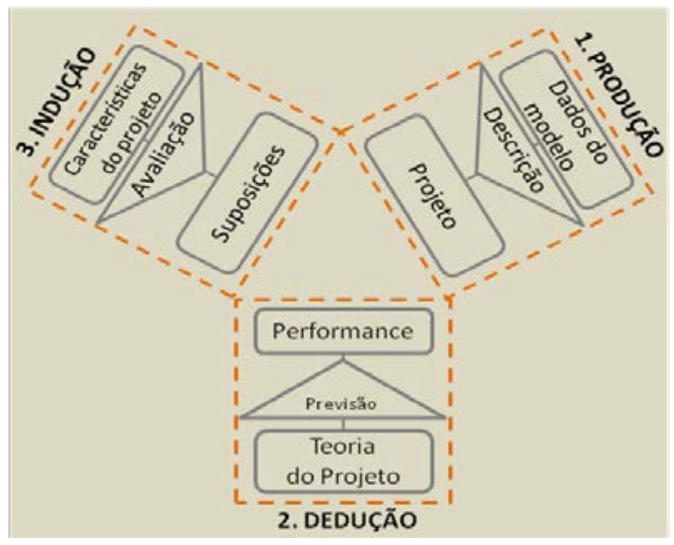

Figura 2: Fluxo proposto por CROSS (2008); VAN DER LINDEN; LACERDA (2012)

Fonte: elaborado pelo autor, com base na pesquisa realizada, 2016.

Considerado como um modelo cíclico, este se distribui em três macros etapas. Inicia com a etapa de produção que compreende os requisitos preliminares e pressupostos sobre tipos de soluções que produzem ou descrevem um conceito de projeto. Em seguida avança para a etapa de dedução que prevê o seu desempenho e passa por um momento de indução indicando mudanças e refinamentos no conceito (VAN DER LINDEN; LACERDA, 2012). Novos desdobramentos foram sendo incorporados na estrutura do fluxo metodológico de design. Um modelo proposto pelo Design Council (2007), nomeado de diamante duplo, representa movimentos divergentes, de busca e exploração, e os convergentes, de seleção e definição.

O modelo do diamante duplo nos processos de divergência compreende as fases descobrir e desenvolver enquanto que nos processos de convergência as fases definir e distribuir. As atividades exploratórias e de concentração são alternadas ao longo do processo, mostrando os diferentes modos de pensamento dos designers (DESIGN COUNCIL, 2007; VAN DER LINDEN; LACERDA, 2012). Este modelo permite alcançar a inteligência de projetos que leva a escolha da melhor solução.

A partir da mudança de cenário, com o advento das complexidades que foram sendo incorporadas ao design, identificando-se assim, novas configurações na estrutura dos fluxos. Assim, passam a buscar por elementos que representam as complexidades e um olhar sistêmico sobre o contexto. Nessa perspectiva, surge o design thinking que apresenta uma proposta cíclica e que estabelece um modelo flexível para o processo de design. Segundo Brown (2008), a estrutura metodológica do design thinking se difere do 
processo linear, anteriormente apresentado, e rompe com os marcos rígidos dos fluxos apresentados até aqui. $O$ novo modelo se desdobra em três etapas, sendo que nas duas primeiras se direcionam a refinar idéias e oferecer condições para tomada de decisão, conforme a figura 3 :

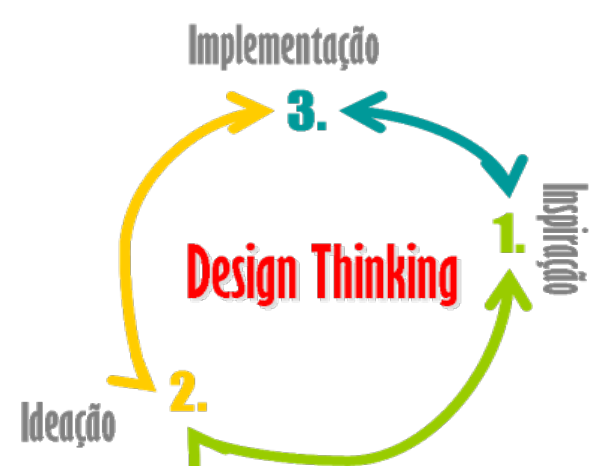

Figura 3: Fluxo proposto por: Brown (2008)

Fonte: Disponível em: http://migre.me/tRchc

O processo cíclico inicia com a etapa de inspiração que corresponde às circunstâncias que motivam a busca de uma solução, sejam elas um problema, uma observação ou ambos. Em seguida avança para a etapa de ideação que compreende o processo de geração, desenvolvimento e teste de idéias que poderão levar a uma solução. Se encerra na etapa de implementação que considera o lançamento do produto/solução/serviço ao mercado/contexto social no qual se insere (VAN DER LINDEN; LACERDA, 2012; BROWN, 2008).

Essas etapas ao longo dos anos sofreram variações e desdobramentos em sua configuração, devido às constantes mudanças do cenário atual. Esses procedimentos continuam sendo uma importante referência para a base do ensino em design até os dias de hoje. Contudo, observa-se que projetar considerando a complexidade requer do designer novas capacidades que Ihe permitam atuar identificando a relação sistêmica da natureza dos problemas na sociedade contemporânea (KRUCKEN, 2008; MORAES, 2008).

Diante às constantes mudanças da sociedade rumo à configuração de um cenário cada vez mais complexo, Cardoso (2013) afirma que a metodologia do design, construída para a resolução de problemas da indústria e do mercado, se volta para refletir sua capacidade de proposição de soluções de uma maneira mais holística e sistêmica (CARDOSO, 2013; MORAES, 2010; CELASCHI e MORAES, 2013). Nesse sentido, compreender as mudanças pelas quais a metodologia do design passou ao longo das últimas décadas permitirá identificar os rumos para uma nova configuração capaz de atender as complexidades do cenário atual.

\section{METODOLOGIA DO DESIGN APLICADA A PRÁTICA PROJETUAL}

Devido ao aumento da complexidade e a percepção de que não seria mais possível conduzir os processos de criação e desenvolvimento baseados apenas na intuição dos designers, foi introduzida no curso de design de ambientes da UEMG a metodologia do design. Nesse sentido, essa mudança foi um importante marco na configuração do curso, que passou a considerar como parte do processo de concepção de solução projetual a sistematização de etapas para resolução de problemas de design. Para maior compreensão das etapas compreendidas no processo da disciplina de prática projetual do 
CDA/UEMG, segue abaixo figura 6 com o fluxo da metodologia de design aplicada a projetos. Tal fluxo tornou-se referência para construção das etapas de elaboração dos projetos de design do CDA/UEMG, conforme pode ser observado na figura 4:

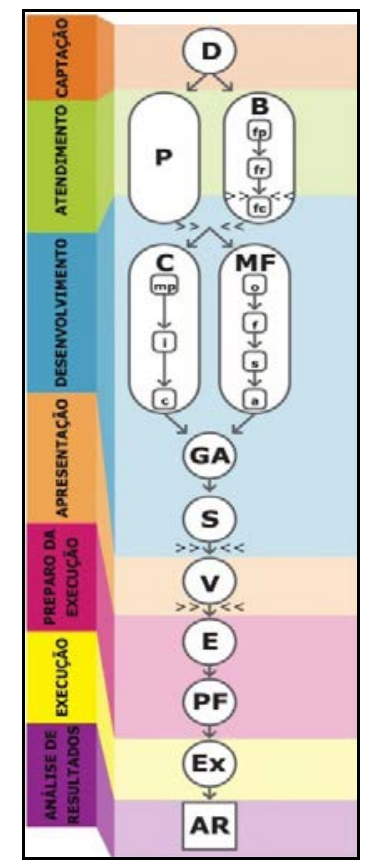

Figura 4: Fluxo metodológico de design de ambientes.

Fonte: ABREU (2015)

O fluxo apresentado foi configurado em concordância com os modelos anteriormente apresentados neste artigo. Apresenta em sua configuração a linearidade no sequenciamento das etapas. Aponta um desdobramento na etapa de conceituação e mapeamento funcional para atender especificidades da tipologia de projetos de design de ambientes. Pode-se perceber que o fluxo obedece a uma configuração linear que inicia pela identificação da tríade: problema, demanda e briefing; em seguida passa pelas etapas de conceito e mapeamento funcional, que se estabelecem paralelamente; geração de alternativas; definição da solução; verificação; elaboração do detalhamento técnico; execução e verificação dos resultados.

\section{RELATO DE EXPERIÊNCIA}

A seguir será apresentado um relato de experiência de ensaios sobre a aplicação da metodologia do design aplicada na disciplina de Prática Projetual I, lecionada no 3 o período do CDA/UEMG no 1 을 semestre de 2016, conforme figura 5: 


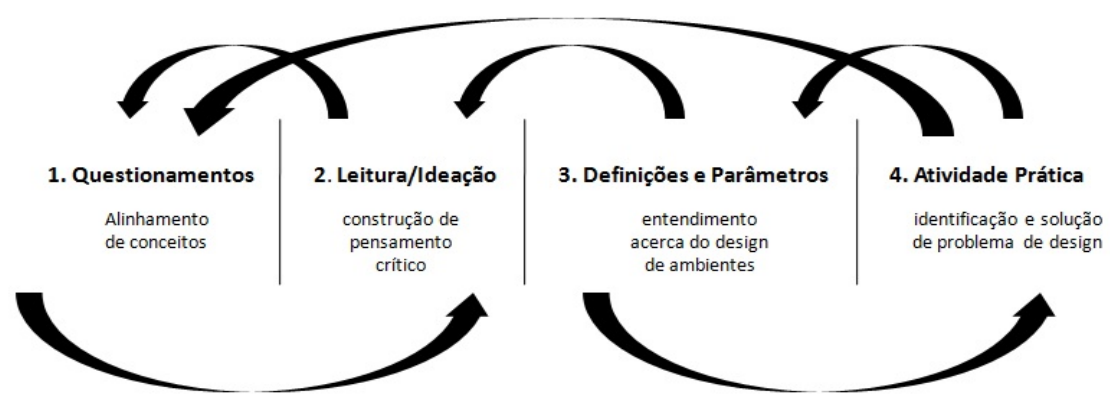

Figura 5 - Etapas de desenvolvimento do conteúdo a ser lecionado na disciplina Prática Projetual I. Fonte: elaborado pelo autor, com base na pesquisa realizada, 2016.

Como forma de introduzir a Prática Projetual aos alunos, foram abordados assuntos como: o que é gestão, o que é Design de Ambientes e no que se consiste a Prática Projetual; de forma que, primeiramente, os alunos apresentaram seu ponto de vista sobre os temas, e posteriormente foram conduzidos a discutir e defender suas divergentes opiniões, objetivando desta forma gerar no aluno a possibilidade de expressar e sintetizar de maneira autônoma os conteúdos propostos.

Posteriormente, visando agregar aos alunos conhecimentos de áreas afins ao Design de Ambientes, e levá-los a uma reflexão acerca da complexidade das soluções dos problemas de Design, foi apresentado e discutido um artigo cujo conteúdo munia os alunos de um referencial teórico sobre a gestão aplicada à prática projetual. Além disso, foi proposta uma atividade conjunta que ocorreu da seguinte forma: foram sorteados entre os alunos palavras que nomeavam áreas correlacionadas ao design; posteriormente ocorreu uma discussão sobre essas áreas levando-os a definição de palavras que sintetizassem a forma com que essas áreas poderiam contribuir na prática com o Design. Depois disso os alunos deveriam classificar tais palavras como: pé no chão (relações já bem estabelecidas e aplicadas com naturalidade); pé no espaço (relações onde existam um grau de impedimento demasiadamente elevado para que sejam executadas); e céu estrelado (relações existentes e pertinentes de acontecerem mas, que não são executadas com naturalidade). Essa atividade está representada na figura 6:

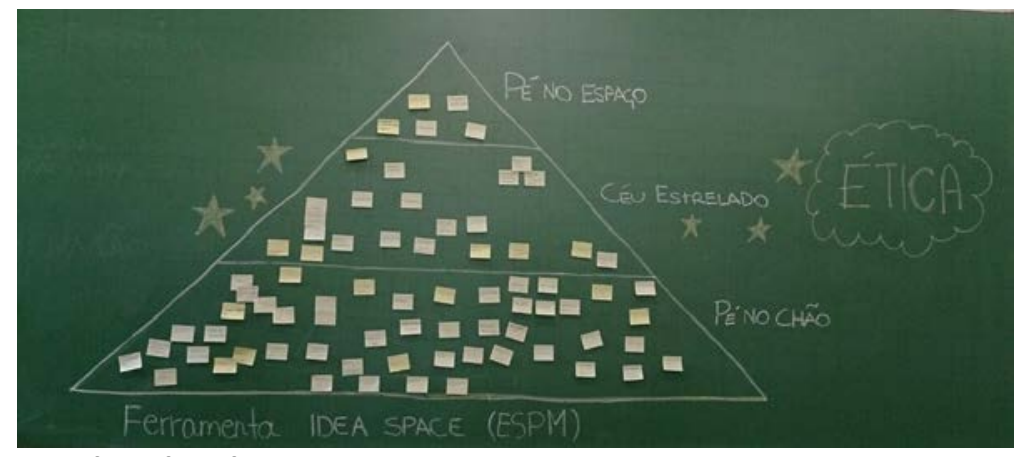

Figura 6 - Quadro montado pelos alunos.

Fonte: elaborado pelo autor, com base na pesquisa realizada, 2016.

A fim de sanar os questionamentos provocados nos alunos a partir das reflexões propostas, foram conduzidas aulas de exposição de conteúdos, abordando: a metodologia de Design aplicada ao projeto; a evolução dos métodos; o que é projeto no contexto do Design; e expostos os diferentes tipos de metodologia que podem ser utilizadas pelo Designer na prática projetual. Além disso, foi apresentada a distinção entre ambiente, arranjo e ambiência no contexto do espaço residencial, e posteriormente proposto uma 
atividade em que deveriam identificar a setorização de 03 ambientes representados em planta arquitetônica de suas residências e propor novas setorizações e analisar o fluxo dos ambientes considerando os aspectos normativos de dimensionamento.

Com os alunos já apropriados acerca dos conhecimentos de embasamento da Prática Projetual, e visando o aprendizado por meio de exemplos, foi proposto um trabalho prático que o tema giraria em torno da alimentação, e se consistiu na tarefa de escolher um cliente real e projetar uma cozinha atendendo suas necessidades.

Como forma de conduzi-los nesse processo de solução de problemas, foram apresentados vídeos e solicitado resenha para provocar reflexões sobre novos modos e hábitos alimentares da atualidade e demandas futuras. Foi também apresentado um conteúdo teórico acerca do primeiro contato com o cliente, as formas de elaboração de um Briefing, e formas de elaboração e condução da Pesquisa Aplicada. Munindo os alunos de referencial teórico para a execução da atividade.

No momento seguinte, foi apresentado o conteúdo acerca do processo de Conceituação e Mapeamento Funcional no projeto de Design. Posteriormente os alunos foram conduzidos a uma atividade onde deveriam confeccionar 03 painéis que representassem, no primeiro o estilo de vida de seu cliente; no segundo as sensações percebidas através do primeiro; e no terceiro ícones que sintetizassem as sensações percebidas no segundo painel. A partir desses painéis os alunos deveriam elaborar sua inspiração e conceito. Possibilitando, com a realização dessa atividade, uma contribuição coletiva através das interações entre os discentes e instruções dos docentes, trazendo uma maior maturidade e segurança nesse primeiro contato dos alunos com o processo de conceituação.

No encontro seguinte os alunos apresentaram os painéis aos colegas e professores; conduzindo-os a demonstrar a interpretação que tiveram de seus clientes, e fundamentar suas escolhas de inspiração e conceito, conforme figuras 7 e 8 :
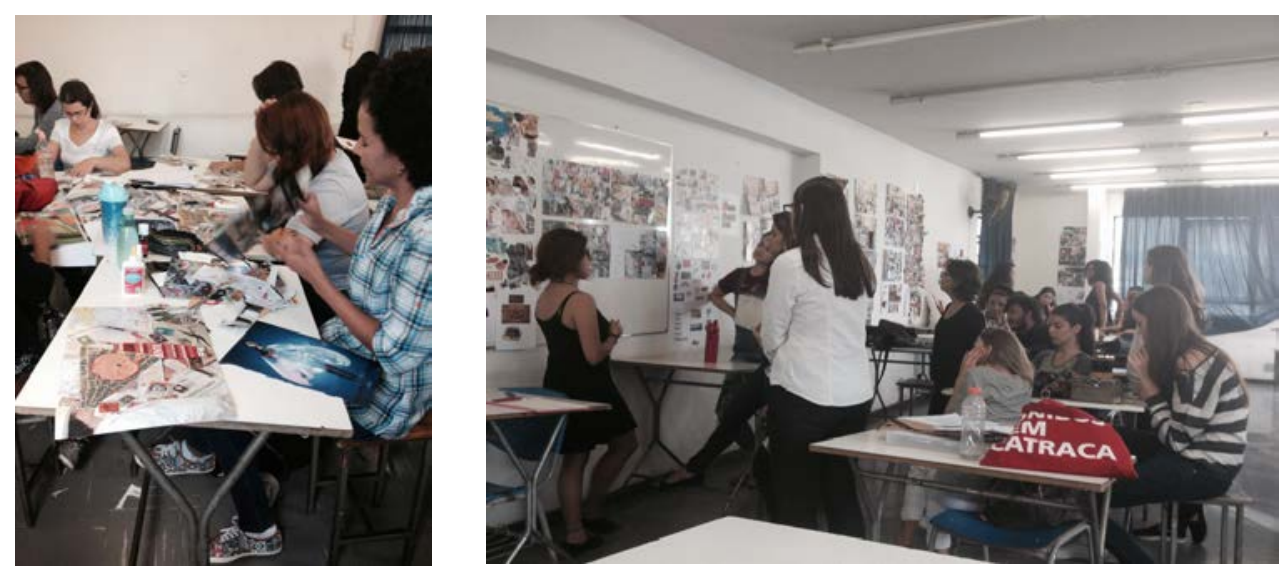

Figura 7 - Processo de elaboração dos painéis Figura 8- apresentação dos painéis para os colegas e professores.

Fonte: elaborado pelo autor, com base na pesquisa realizada, 2016.

Prosseguindo com a realização da atividade, os alunos tiverem encontros onde foram orientados de maneira individual pelos professores acerca da elaboração do Mapeamento Funcional (organograma, fluxograma e setorização), e Geração de Alternativas de Layout, sendo conduzidos a chegarem à solução de Layout que melhor atenderia as suas demandas. 
Dessa forma, pode-se observar a que cultura de Prática Projetal I visava uma atuação tecnicista. Entretanto, a proposta de tema considerou um olhar sistêmico e que direcionasse os alunos para identificar problemas e clientes reais. Aglutinando os diversos conhecimentos teóricos, que os alunos já adquiriram ao longo do curso e aplicados de maneira prática visando levá-los ao encontro de soluções para os problemas de Design de Ambientes.

\section{CONTRIBUIÇÕES PARA O ENSINO EM DESIGN}

Pensar novos modelos metodológicos exige a reflexão sobre novas formas de responder aos problemas apresentados no atual cenário complexo. Sobre a metodologia do design, pode-se notar que a mesma passou por várias transformações. Inicialmente se configurava por um formato linear que se desdobrou na atualidade em modelos cíclicos. Esses modelos consideram a inter-relação que pode haver entre as etapas ao longo do processo, e permitem ao designer uma visão sistêmica e holística ao longo de uma ação de design.

Sobre o relato de experiência apresentado, identifica-se que processos participativos permitem o desenvolvimento da autonomia, análise crítica e processos de aprendizagem mais satisfatórios durante a formação do designer. Ao criar um espaço para o diálogo e a cooperação, contribui-se para a construção de um novo modelo de atuação em design. Acredita-se que a disciplina de Prática Projetual, por sua configuração teóricoprática, configura-se como um espaço adequado para se projetar novos caminhos e processos de design.

Pelo caráter de artigo científico entende-se que o estudo não pretende esgotar os questionamentos relativos à compreensão e o desenvolvimento da prática projetual em design de ambientes. Serve, entretanto, como força motriz para a inserção e o estudo de métodos na academia e o aprimoramento e atualização do ensino de uma forma geral. Observa-se ainda, a necessidade de trabalhos futuros que abarquem tais questões em instâncias mais profundas.

\section{REFERÊNCIAS}

ABREU, Simone Maria Brandão Marques. Aspectos subjetivos relacionados ao Design de Ambientes: um desafio no processo projetual 2015, 135 f. Dissertação (Mestrado em Design), Programa de Pós-Graduação em Design da Universidade do Estado de Minas Gerais, Belo Horizonte, 2015.

BAXTER, Mike. Projeto de produto: guia prático para o desenvolvimento de novos produtos. São Paulo: Blucher, 1998.

BEZERRA, Charles. O Designer Humilde: lógica e ética para inovação. São Paulo: Rosari, 2008.

BONSIEPE, Gui. A Tecnologia da Tecnologia. São Paulo: Blucher, 1983.

BOURDIEU, P. Esquisse d'une théorie de la pratique. Tradução das partes: "Les trois modes de connaissance" e "Structures, habitus et pratiques". In: -. Esquisse d'une théorie de la pratique. Geneve, Lib. Droz, 1972. p. 162-89. Traduzido por Paula Montero. 
BROWN, T. Design thinking. Harvard Business Review, p. 84-92, june 2008. Disponível em: http://www.ideo.com/images/uploads/thoughts/IDEO_HBR_Design_Thinking.pdf.

Acesso em: 24 nov. 2011.

BÜRDEK, Bernard E. História, Teoria e Prática do Design de Produtos. Tradução de Freddy Van Camp. São Paulo: Blücher, 2006.

CARDOSO, Rafael. Design para um mundo complexo. São Paulo: Cosac Naify, 2013. 264p.

Uma Introdução à História do Design. São Paulo: Blücher, 2000.

CASANOVA, José Luiz. A teoria da prática: uma prática menos teorizada. Revista Sociologia: Problemas e Práticas. №17, p.61 a 73, 1995.

CELASCHI, F.; MORAES, D. Futuro, bem-estar, interdependência: palavras-chave para o design contemporâneo. Cadernos de Estudos Avançados em Design - design e humanismo - 2013 - p. 35-60.

CROSS, N. engineering design methods. Chichester: John Wilwy \& Sons, 2008.

DESIGN COUNCIL. Eleven Lessons: managing design in eleven global companies. 5 nov. 2007. Disponível em: http://designcouncil.org.uk/Documents/

Publications/Desk\%20Research\%20Report.pdf. Acesso em: 15 dez. 2009.

DIAS, Maria Regina Álvares Correia. O Ensino Do Design: a interdisciplinaridade na disciplina de projeto em design. Programa de Pós-Graduação em Engenharia de Produção. Universidade Federal de Santa Catarina. Dissertação de Mestrado. Florianópolis, 2004.

FRANCO, Jane E. Monteiro; ARAÚJO, Maria Antonieta. Projeto Pedagógico curso de design de ambientes. Escola de Design da UEMG. Belo Horizonte, Setembro, 2003.

ICSID 29ạ Assembleia Geral realizada em outubro de 2015 em Gwangju, Coréia do Sul. Disponível em: <http://migre.me/tLaoF>. Acesso no dia 15/04/2016.

KRUCKEN, Lia. Competências para o design na sociedade contemporânea. In: Caderno de estudos avançados em design - transversalidade, caderno 2, v.1, Dijon de Moraes e Lia Krucken (org.), 2008.

LÖBACH, Bernd. Design Industrial: Bases para a configuração dos produtos industriais. Tradução de Freddy Van Camp. São Paulo: Blucher, 2001.

MALDONADO, Tomás. Design Industrial. Tradução de José Francisco E. M. Lisboa: Edições 70, 1999.

MORAES, Dijon de. Metaprojeto como modelo projetual. In: Strategic Design Research Journal, 3(2): 62-68 maio-agosto, 2010.

MOREIRA, Samantha. C. O. Interiores de Casas Residenciais em Belo Horizonte: a década de 1950. 2006. 137f. Dissertação (Mestrado em História) - Faculdade de Filosofia e Ciências Humanas da Universidade Federal de Minas Gerais, Belo Horizonte, 2006.

MOZOTA, Brigite Borja de. Gestão do design: usando o design para construir valor de marca e inovação corporativa. Porto Alegre: Bookman, 2011.

VAN DER LINDEN, Júlio Carlos de Souza; LACERDA, André Pedroso. Metodologia projetual em tempos de complexidade. In: Pelos caminhos do design: metodologia de projeto. 
MARTINS, Rosane Fonseca de Freitas e VAN DER LINDEN, Júlio Carlos de Souza (organizadores). Londrina: EDUEL, 2012.

VIANNA, Maurício. Design thinking: inovação em negócios. Rio de Janeiro: MJV Press, 2012. 